\title{
Nugget shifting in resistance spot welding of multi-stackup sheets
}

\author{
by Jie Shen ${ }^{* *}$, Yansong Zhang ${ }^{* *}$ and PC Wang ${ }^{* * *}$
}

\begin{abstract}
In order to investigate the weld nugget shifting phenomenon in resistance spot welding, a combined thermal-mechanical-electrical finite element model was developed to analyze the weld nugget formation process during welding. It was found that when the thickness of the bottom sheet increases, the degree of weld nugget shifting would become serious which will lead to the unqualified weld nugget. For the welding joint with material combination of SAE1004 + SAE1004 + DP600, the critical thickness combination is $0.6+1.8+2.0 \mathrm{~mm}$. To improve the weld nugget shifting of the multi-stackup sheets joint, different electrode tips were used in the welding process. The effectiveness of this method was validated by the metallographic pictures.
\end{abstract}

Key Words: Nugget shifting, Resistance spot welding, Multi-stackup sheets, Different electrode tips

\section{Introduction}

With the demand of lightweight vehicle structures, resistance spot welding (RSW) of multi-stackup steel sheets is increasingly applied in some complex structures such as front longitudinal rails, $\mathrm{A}, \mathrm{B}$, and $\mathrm{C}$ pillars, and the bulkhead to inner wing. However, due to the difference in mechanical and physical properties for different sheet grade, the weld nugget of RSW would not locate in the center of the welding joint and shift to one side. This shifting phenomenon would lead to the bad weldability and weld quality of the welding joint with multi-stackup sheets. Therefore, it is essential to obtain an understanding of the welding process and the weld nugget shifting phenomenon of RSW with multi-stackup sheets ${ }^{1)}$.

It is difficult to obtain insightful information on the welding process by experiments alone because of the coupled interactions between electrical, thermal, mechanical and metallurgical phenomena of RSW. Fortunately, numerical modeling provides a powerful tool in studying these interactions ${ }^{2-3)}$. Recently, many modeling studies have been carried out on the numerical modeling of RSW. Nied ${ }^{4)}$ has developed a simplified finite element model (FEM) to investigate the effect of the electrode geometry on the deformation and stresses as a function of temperature. Furthermore, sophisticated FEM models which considered temperature-dependent material properties, contact status, phase transformation, and coupled field effects into the simulation of RSW have also been reported in the literature ${ }^{5)}$. Nevertheless, the simulation of the RSW of multi-stackup steel sheets is still lacking.

In this study, a combined thermal-mechanical-electrical

${ }^{*}$ Received: 2010.11.12

${ }^{* *}$ State Key Lab of Mechanical System and Vibration,

Shanghai Key Lab of Digital Autobody Engineering, Shanghai Jiao Tong University, Shanghai, China

${ }^{* * *}$ China Science Lab, General Motors Research \&

Development Center, Shanghai, China incremental model has been developed to reasonably predict the nugget formation in RSW and analyze the weld nugget shifting phenomenon. Then, a method by using different electrode tips is brought up to improve the weld quality of multi-stackup sheets. These calculations and experimental results would provide guidance in the selection of sheet thickness and weld quality improvement for RSW of multi-stackup assemblies.

\section{Nugget shifting analysis based on FEA}

\subsection{Setup of finite element model}

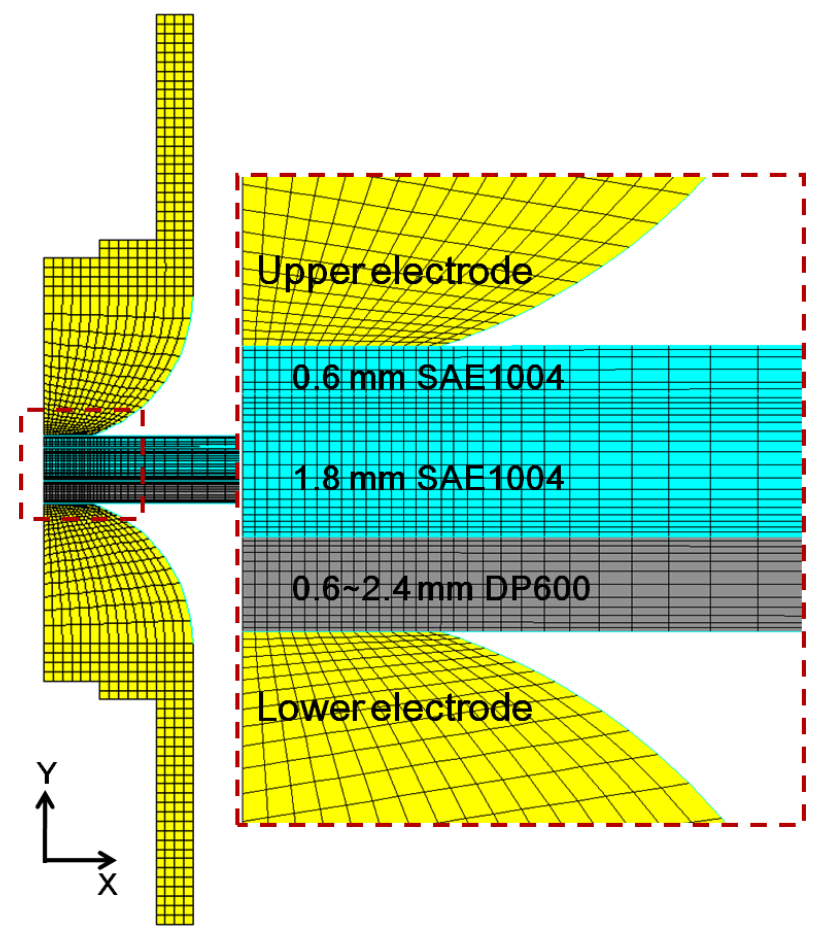

Fig. 1 FEM model for resistance spot welding

A computational model based upon the software ANSYS 
program is developed to describe the welding process and weld nugget shifting phenomenon of the RSW of three sheets. Figure 1 presents the associated element grid of the two-dimensional axi-symmetric model. As shown, four-node axi-symmetric elements (i.e. PLANE67) were used to model the electrode and steel sheets. Special contact elements were used to model the regions where the contact state of sheet-to-sheet and sheet-to-electrode exist. The finite element grid in Fig. 1 has 2656 elements and 2651 nodes. As shown, the grid is graded from fine to coarse, according to the expected reduction in temperature gradient on moving away from the heat source. The detailed governing equations, boundary conditions and numerical method are given in our previous paper ${ }^{6}$.

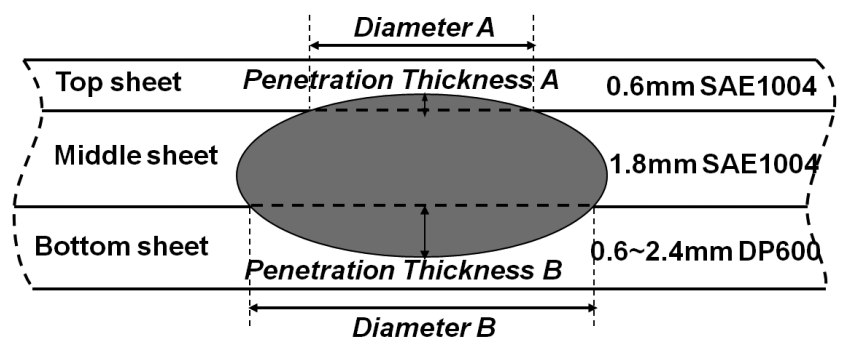

Fig. 2 Weld nugget configuration and dimensions for resistance spot welding of multi-stackup steel sheets

Figure 2 shows an example of multi-stackup steel sheets with various sheet gages and material properties. Galvanized coated low carbon steel (SAE1004) and high strength steel (DP600) was used in this study. A weld nugget will develop first at the sheet-to-sheet interface, and then in an increasing volume of material about the sheet-to-sheet interface. At the completion of weld cycle, the current is shut off and the hold cycle begins. The water-cooled copper electrodes extract a significant quantity of heat from the weld area. Because the electrodes are in contact with sheets, the weld region is effectively quenched. Finally, the electrodes are retracted and a completed weld is developed. To investigate the weld quality and the weld nugget shifting, the two weld nugget diameters and weld nugget penetration thicknesses were brought out and shown in Fig. 2.

Table 1 Welding parameters for multi-stackup steel sheets

\begin{tabular}{ll}
\hline Welding parameters & Value \\
\hline Electrode force $(\mathrm{kN})$ & 5.5 \\
Welding current $(\mathrm{kA})$ & 9.5 \\
Squeezing time $(\mathrm{ms})$ & 200 \\
Welding time $(\mathrm{ms})$ & 460 \\
Hold time $(\mathrm{ms})$ & 100 \\
\hline
\end{tabular}

The typical sheet combination of multi-stackup sheets for simulation is $0.6 \mathrm{~mm}$ SAE1004 $+1.8 \mathrm{~mm} \mathrm{SAE} 1004+1.2 \mathrm{~mm}$ DP600. Resistance spot welding of multi-stackup steel sheets was prepared using a DC current. The tip diameters of the two electrodes are $5.0 \mathrm{~mm}$. The welding parameters for RSW of 0.6 $\mathrm{mm} \mathrm{SAE} 1004+1.8 \mathrm{~mm} \mathrm{SAE} 1004+1.2 \mathrm{~mm}$ DP600 are given in Table 1.

\subsection{Result and discussion of nugget shifting analysis}

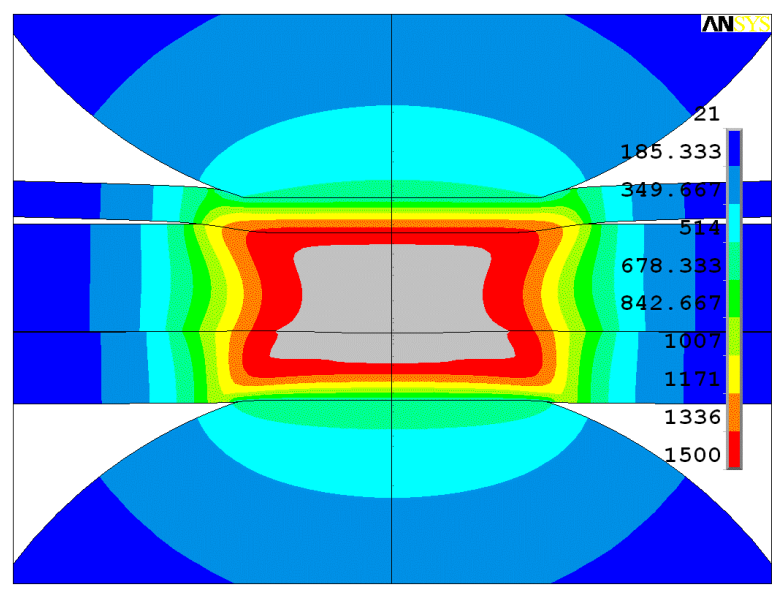

(a) $240 \mathrm{~ms}$

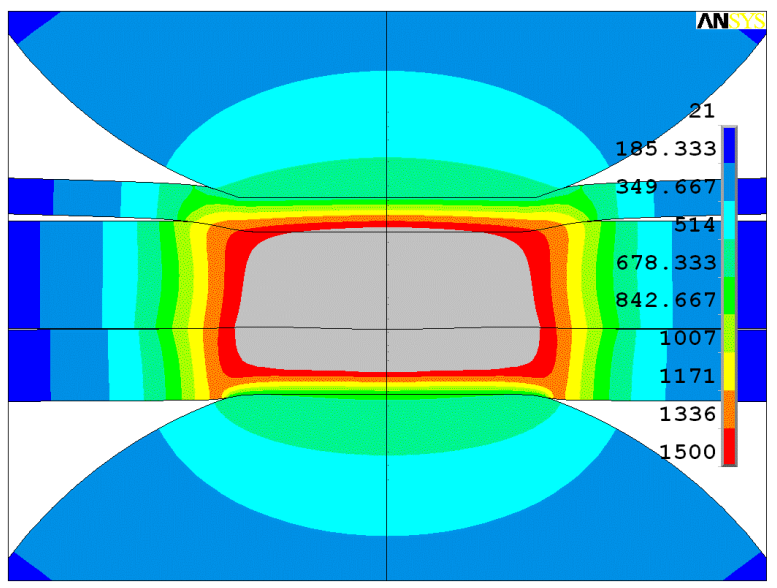

(b) $360 \mathrm{~ms}$

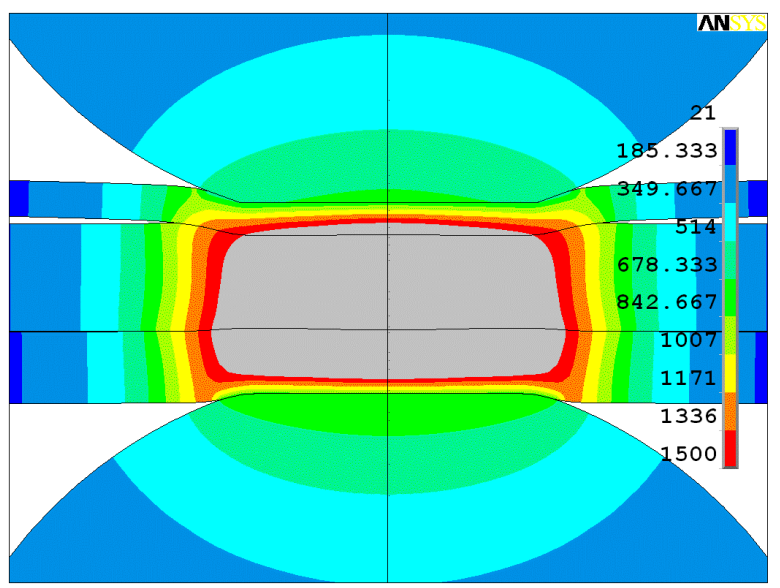

(c) $460 \mathrm{~ms}$

Fig. 3 Temperature field during the welding process for $0.6 \mathrm{~mm}$ SAE1004 $+1.8 \mathrm{~mm} \mathrm{SAE} 1004+1.2 \mathrm{~mm}$ DP600 under a welding current of $9.5 \mathrm{kA}$

Before applying the electrical current, an electrode force is 
applied to bring the workpieces into intimate contact. The electrode-to-sheet and sheet-to-sheet deformation influences the weld current density. After applying the welding current, the temperature of the sheets would rise by the generation of the joule heat. Figure 3 shows the temperature distributions for the welding times of $240 \mathrm{~ms}, 360 \mathrm{~ms}$ and $460 \mathrm{~ms}$ under an electrode force of $5.5 \mathrm{kN}$ and a welding current of $9.5 \mathrm{kA}$, respectively. Firstly, high temperature has built up at two faying interfaces between the multi-sheets. As the welding time is increased to $240 \mathrm{~ms}$ in Fig. 3(a), the temperature of the steel around the middle-to-bottom sheet interface reaches the melting point (about $1500^{\circ} \mathrm{C}$ ) first. Then, the weld nugget initiates around the lower part of the whole joint with $0.6 \mathrm{~mm}$ SAE1004 + 1.8mm SAE1004 + $1.2 \mathrm{~mm}$ DP600 At the welding time of $360 \mathrm{~ms}$ shown in Fig. 3(b), the weld nugget grows up and leads to the melting of the top sheet at the top-to-middle interface. This indicates that the weld nugget around the top-to-middle interface begins to form at this time. The difference between the initial times of the weld nugget on the two interfaces is considered to be an important reason for the weld nugget shifting phenomenon. As shown is Fig. 3(c), the welding time is increased to $460 \mathrm{~ms}$, the final weld nugget of multi-stackup steel sheets interfaces forms. It could be seen that the diameter $\mathrm{A}$ and the penetration thickness $\mathrm{A}$ are smaller than the diameter $\mathrm{B}$ and the penetration thickness $\mathrm{B}$. This could prove that the weld nugget shifting phenomenon exist in the RSW joint of $0.6 \mathrm{~mm} \mathrm{SAE} 1004+1.8 \mathrm{~mm}$ SAE1004 + $1.2 \mathrm{~mm}$ DP600

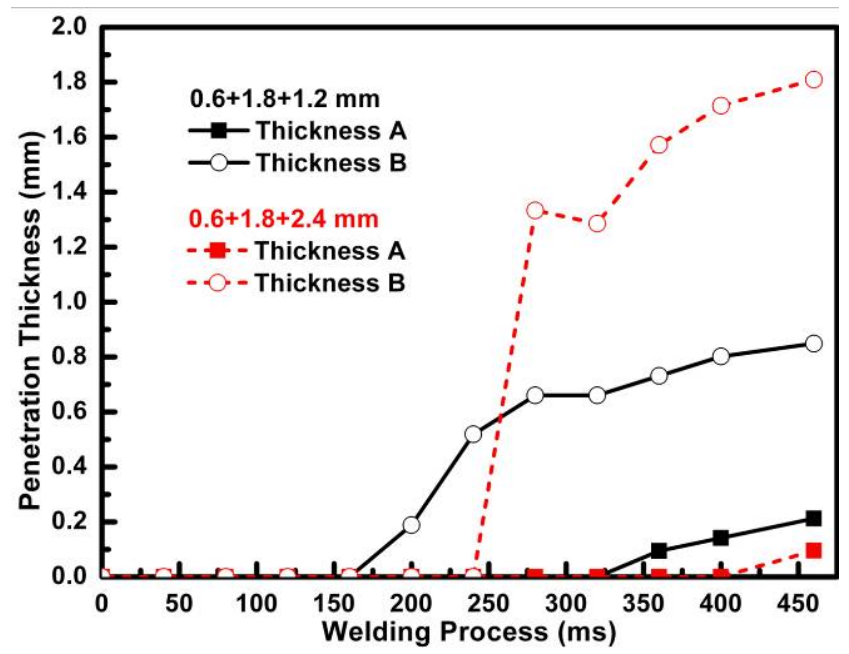

Fig. 4 Welding process with different thickness of bottom sheet

The weld nugget formation process would change for different sheet combination. Figure 4 shows the change history of the penetration thickness during the welding process for two different sheet combinations. The results shows that when the thickness of bottom sheet increase from $1.2 \mathrm{~mm}$ to $2.4 \mathrm{~mm}$, the initial times of the weld nugget on the two interfaces are both delayed. Thus, the penetration thickness A of $0.6+1.8+2.4 \mathrm{~mm}$ is smaller than that of $0.6+1.8+1.2 \mathrm{~mm}$. However, the penetration thickness B of $0.6+1.8+2.4 \mathrm{~mm}$ is much bigger than that of $0.6+1.8+1.2$ $\mathrm{mm}$. This is due to the great body resistance and bad cooling capacity of the $2.4 \mathrm{~mm}$ sheet comparing to the $1.2 \mathrm{~mm}$ sheet.

Since the sheet thickness has a significant effect on the weld nugget formation process and penetration thickness, it would be useful to know how the sheet thickness affects the weld nugget shifting phenomenon and the weld quality. To study the effect of sheet thickness combination on the weld quality, the thickness of the bottom sheet (DP600) was varied from $0.6 \mathrm{~mm}$ to $2.4 \mathrm{~mm}$, while the gages of the top and middle sheets (SAE1004) are fixed at $0.6 \mathrm{~mm}$ and $1.8 \mathrm{~mm}$, respectively. Weld nugget penetration thicknesses were calculated by the FEM model and the results are shown in Fig. 5. It could be seen that when the thickness of the bottom sheet increases from $0.6 \mathrm{~mm}$ to $2.4 \mathrm{~mm}$, the penetration thickness A around the top-to-middle interface decreases, while the penetration thickness B rises up quickly. This result indicates that the weld nugget shifting phenomenon would become more and more serious when the thickness of bottom sheet increases.

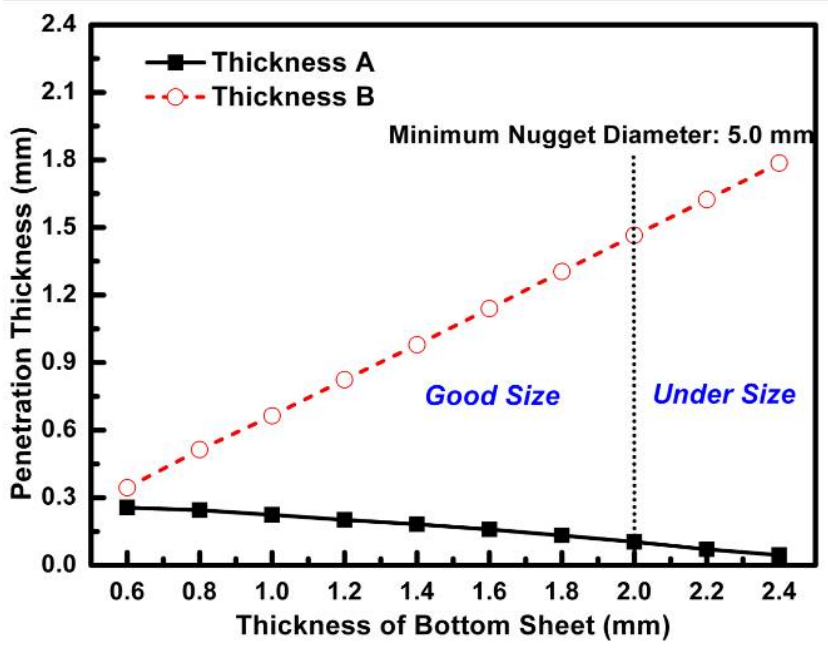

Fig. 5 Effect of the sheet combination on the weld nugget shifting

According to the American Welding Society (AWS) standard ${ }^{7)}$, the minimum weld nugget diameter for the calculated sheet combination is $5.0 \mathrm{~mm}$. Thus, it could be found that when the thickness of the bottom sheet is less than $2.0 \mathrm{~mm}$, the weld nugget could reach a good size and the weld quality is satisfactory. If the bottom sheet is thicker than $2.0 \mathrm{~mm}$, the great weld nugget shifting phenomenon would lead to a under size weld nugget. So, the critical thickness combination is $0.6+1.8+2.0 \mathrm{~mm}$ for the welding joint with material combination of SAE1004 + SAE1004 + DP600

\section{Control of nugget shifting by different electrode tips}

\subsection{Experimental Setup for different electrode tips}


To control the weld nugget shifting and improve the weld nugget quality, a method by using different electrode tips are brought up to applied in the RSW of multi-stackup sheets. According to the previous results, the sheet combination $0.6 \mathrm{~mm}$ SAE1004 + $1.8 \mathrm{~mm} \mathrm{SAE1004}+2.2 \mathrm{~mm}$ DP600 would get a under size weld nugget by using the welding parameters listed in Table 1 with two common electrode tips $(5+5 \mathrm{~mm})$. To improve the weld quality, two special electrodes with tip diameters $4 \mathrm{~mm}$ on the $0.6 \mathrm{~mm}$ SAE1004 side and $6 \mathrm{~mm}$ on the $2.2 \mathrm{~mm} \mathrm{DP600}$ side $(4+6 \mathrm{~mm})$ were introduced in the welding experiment.
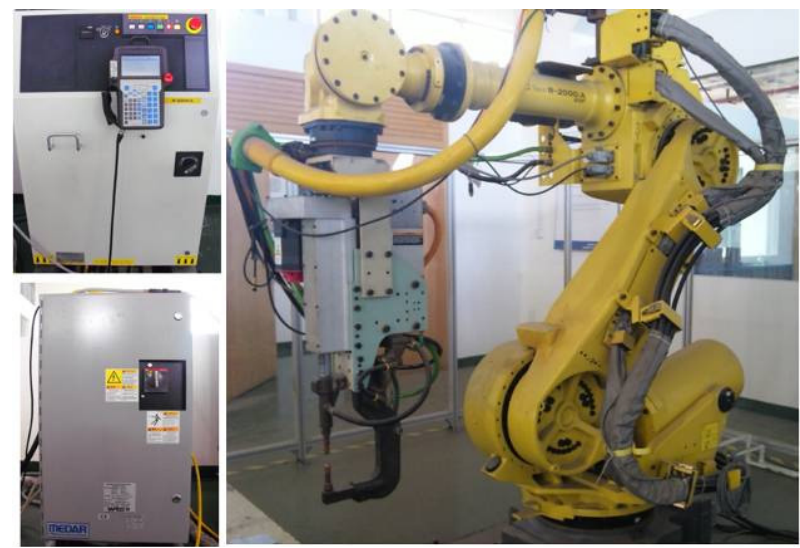

Fig. 6 Servo gun and MFDC welding system

The welding system is composed by servo gun equipped on the FANUC robot and the medium frequency direct current (MFDC) welder, shown in Fig. 6. The welding parameters are listed in Table 1.Galvanized SAE1004 and DP600 were used in this study.
The chemical composition of SAE1004 and DP600 are listed in Table 2 .

Table 2 Chemical Composition (Wt \%) of Steels

\begin{tabular}{cccccccc}
\hline Steel & $\mathrm{C}$ & $\mathrm{Mn}$ & $\mathrm{P}$ & $\mathrm{S}$ & $\mathrm{Si}$ & $\mathrm{Ni}$ & $\mathrm{Cr}$ \\
\hline SAE1004 & 0.037 & 0.21 & 0.01 & 0.02 & 0.018 & 0.013 & 0.027 \\
DP600 & 0.08 & 1.74 & 0.012 & 0.003 & 0.016 & 0.017 & 0.173 \\
\hline
\end{tabular}

\subsection{Experimental result and discussion}

To investigate the effectiveness of the electrode tip $4+6 \mathrm{~mm}$ on the weld nugget shifting during RSW, some metallographic pictures of the nugget formation process were taken and shown in Fig. 7. When the welding time is $180 \mathrm{~ms}$, there were not any sticks on the two interfaces between sheets with $5+5 \mathrm{~mm}$ electrode. However, it could been seen that the $4+6 \mathrm{~mm}$ electrode make the top and middle sheet stick together due to the melted galvanized coating. This is due to that the $4 \mathrm{~mm}$ electrode tip could increase the current density around the top sheet to make the temperature rise more quickly than $5 \mathrm{~mm}$ electrode when the welding current passes through the welding joint. Under this effect of the $4+6 \mathrm{~mm}$ electrode tip, the weld nugget initiated earlier and formed bigger than $5+5 \mathrm{~mm}$ electrode tip at $300 \mathrm{~ms}$ welding time. Thus, when the welding time reached $460 \mathrm{~ms}$, both of the diameter A and the penetration thickness A of the weld nugget were improved by the $4+6 \mathrm{~mm}$ electrode tips.

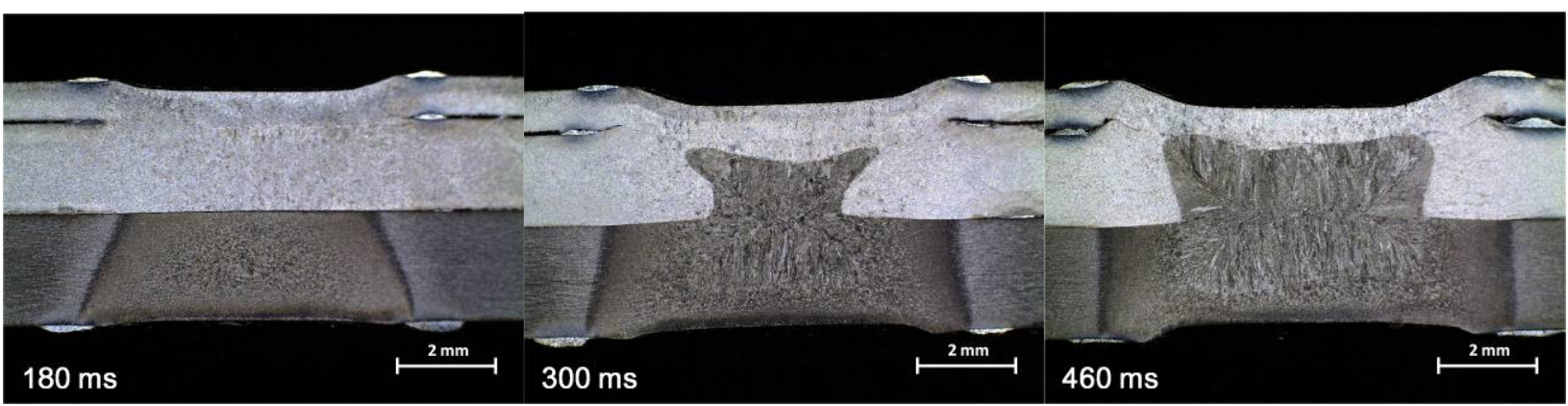

(a) 4+6 mm electrode tips

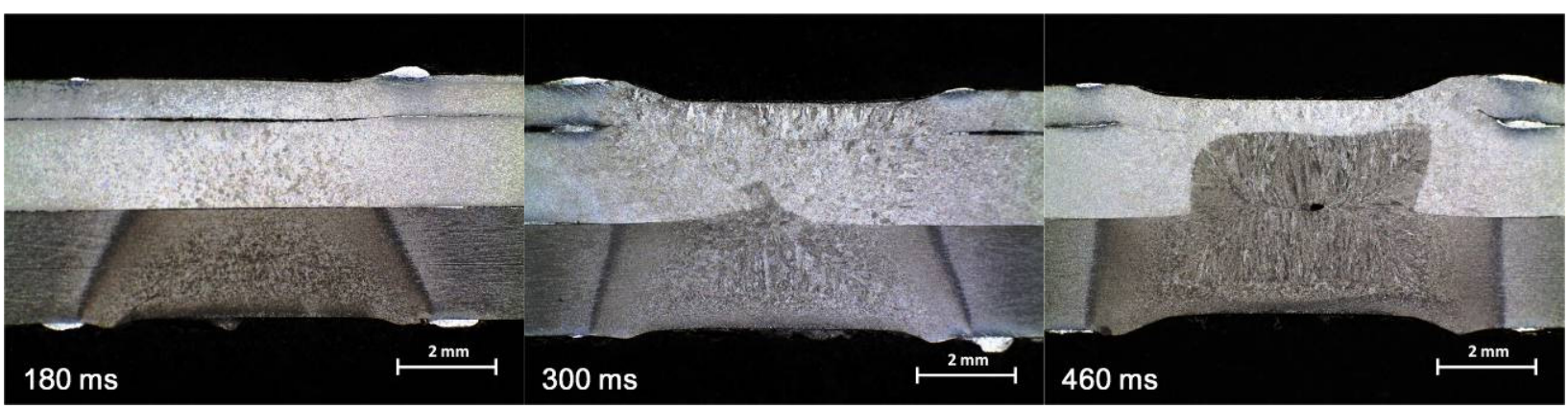

(b) $5+5 \mathrm{~mm}$ electrode tips

Fig. 7 Weld nugget formation of $0.6 \mathrm{~mm}$ SAE1004 + $1.8 \mathrm{~mm} \mathrm{SAE1004} \mathrm{+} 2.2 \mathrm{~mm}$ DP600 with different electrode tips 


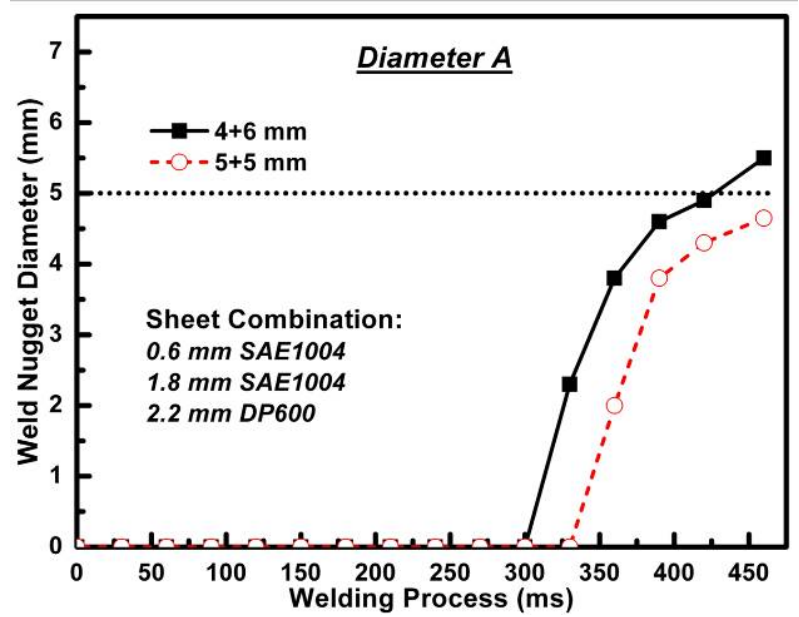

(a) Diameter $\mathrm{A}$

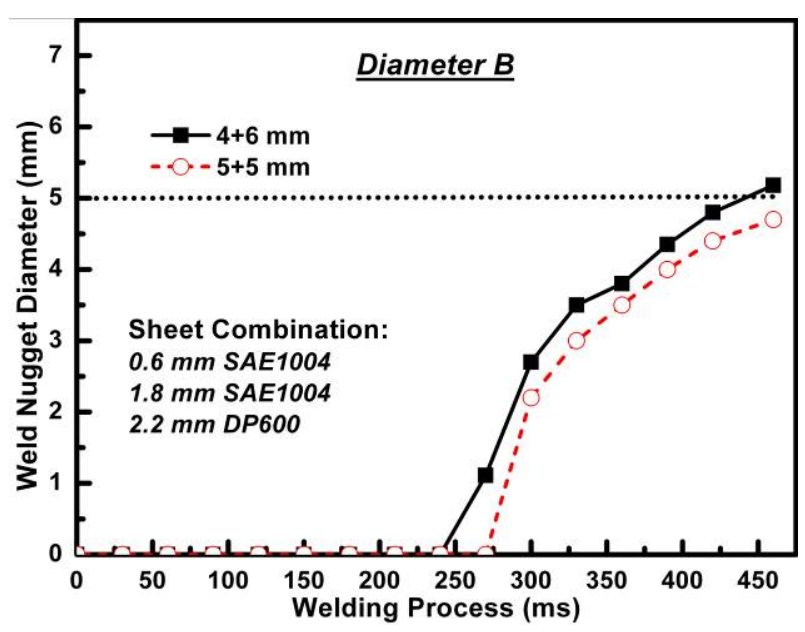

(b) Diameter B

Fig. 8 Comparison of weld nugget diameter during RSW

Figure 8 shows comparison of weld nugget diameter during RSW of $0.6 \mathrm{~mm} \mathrm{SAE} 1004+1.8 \mathrm{~mm}$ SAE1004 + $2.2 \mathrm{~mm}$ DP600 with $4+6 \mathrm{~mm}$ and $5+5 \mathrm{~mm}$ electrode tips. The results show that the two weld nugget diameters with $4+6 \mathrm{~mm}$ electrode tips initialed about $30 \mathrm{~ms}$ earlier than that with $5+5 \mathrm{~mm}$ electrode tips. This would help the weld nugget with $4+6 \mathrm{~mm}$ electrode tips have more time to grow up and finally reach a good nugget size. It could reasonably prove the effectiveness of this method to control the weld nugget shifting of the sheet combination $0.6 \mathrm{~mm}$ SAE1004 + 1.8 mm SAE1004 + 2.2 mm DP600.

\section{Conclusions}

(1) A finite element model was developed to analyze the weld nugget shifting phenomenon in resistance spot welding of multi-stackup sheets. It was found that when the thickness of the bottom sheet increases, the degree of weld nugget shifting would become serious which will lead to the unqualified weld nugget. For the welding joint with material combination of SAE1004+ SAE1004 + DP600, the critical thickness combination is $0.6+1.8$ $+2.0 \mathrm{~mm}$.

(2) It was brought up to control the weld nugget shifting and improve the weld nugget quality by using different electrode tips in resistance spot welding. The effectiveness of this method was validated by the experimental results.

\section{Acknowledgements}

This research was supported by the General Motors Collaborative Research Laboratory at Shanghai Jiao Tong University, the Research Fund of State Key Lab of MSV, China (Grant No. MSV-2010-04) and Project 50905111 supported by National Natural Science Foundation of China.

\section{Reference}

1) Harlin N., Jones T.B. and Parker J.D.: Weld growth mechanism of resistance spot welds in zinc coated steel, J. Mater. Process Technol., 143-144(2003), 448-453.

2) Zhang Y.S., Xu J., Lai X.M. and Chen G.L.: Numerical simulation of spot welding for galvanised sheet steels, Sci. Technol. Weld. Joining, 13(2008), 192-198.

3) Kong X., Yang Q., Li B., Rothwell G., English R. and Ren X.J., Numerical study of strengths of spot-welded joints of steel, Mater. Des., 29(2008), 1554-1561.

4) Nied H.A.: The finite element modeling of the resistance spot welding process, Weld. J., 63(1984), 123s-132s.

5) Khan J.A., Xu L. and Chao Y.: Prediction of nugget development during resistance spot welding using coupled thermal-electricalmechanical model, Sci. Technol. Weld. Joining, 4(1999), 201-207.

6) Jie Shen, Yansong Zhang, Xinmin Lai and P.C. Wang, Modeling of resistance spot welding of multiple stacks of steel sheets', Mater. Des., 32(2011), 550-560.

7) ANSI/AWS/SAE/D8.9-97, Recommended practices for test methods for evaluating the resistance spot welding behavior of automotive sheet steel materials, American Welding Society 1997. 